\title{
Journal of Economics Bibliography
}

www.kspjournals.org

\begin{tabular}{lll}
\hline Volume 4 & December 2017 & Issue 4 \\
\hline
\end{tabular}

\section{A theory of wealth accumulation differences considering modern net savings gradualism the impact of unresolved long run differences in wealth accumulation on the annualized net savings in the USA}

\author{
By James E. CURTIS Jr.
}

\begin{abstract}
In other words, for those who monitor relative wealth accumulation and are unmoved by divine empathy, a disincentive to increase the rate of full manumission is possible. Consider slavery as overt, formal constraints to zero or even negative wealth accumulation; and consider freedom of ex-slaves as the perception of overt lack of formal wealth constraints and yet the possibility of covert, hidden or informal constrained wealth accumulation controls (i.e. southern Jim Crow laws); and finally, consider full manumission as the uninhibited opportunity to accumulate wealth at rates of entities without a history of slavery or with a more limited history of slavery. This definition of full manumission probably includes the necessity of wealth transfers to the fully manumitted ex-slave in transition from slavery or free ex-slave to full manumission. Nevertheless, this negatively bounded correlation between duration of time from the end of enslavement and magnitude of unexplained differences in wealth suggests the magnitude in the unexplained portion of white-black wealth differences increases as the length of time from the real end of enslavement decreases.
\end{abstract}

Keywords. Slavery, Wealth, Inequity, Faith.

JEL. A23, C61, D31, D63.

\section{An introduction to}

$\mathrm{T}$ This concept of negative correlation can be explained in a graph. Graph 1 shows the Theory of the Negatively Bounded Correlation between accumulation of wealth differences among groups and groupings, including groups with hours of work and no wage without minimum constitutional, federal, and international standards. Moreover, Graph 1 shows a negative growth rates of differences in wealth, including discrimination, with improved standards such as personal, private property rights.

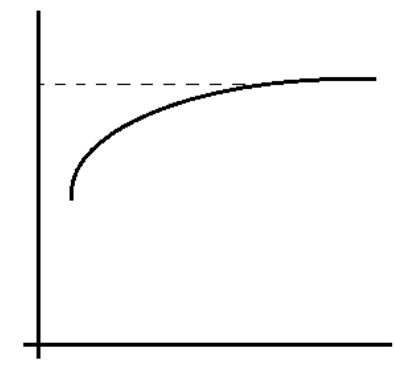

Graph 1. Laws and Wealth Accumulation Differences Source: (Curtis, 2017).

\footnotetext{
${ }^{\dagger}$ Independent researcher, PO Box 3126, Washington, District of Columbia, USA.

こ. + (202) 739-1962

ㅉ. jamesjr@jecjef.net
} 


\section{Journal of Economics Bibliography}

Modern pressures on median income workers to cost minimize and strategically invest, including a low interest-earning bank savings account, suggest the possibility of stagnation in closing the gap of wealth differences among groups. In Table 1, Curtis (2017) annualizes salaries of interns, employees and executives with similar cost considerations, i.e. low-income, median income, and executive income with similar considerations, leading to only gradual differences net savings. Net income stagnation is researchable by considering a model of wealth differences, with theoretical considerations of favoritism and discrimination, presented in Appendix A1 and Appendix A2.

Table 1. Annual Salary Pengelum with Similar Costs Considerations

\begin{tabular}{|c|c|c|c|c|c|c|c|c|c|c|c|c|c|c|}
\hline $\begin{array}{l}\text { Costs/Salary, Annualized } \\
\text { 401K Plan }\end{array}$ & $3,600.00$ & $4,800.00$ & $5,200.00$ & $10,400.00$ & $13,000.00$ & $15,600.00$ & $26,000.00$ & $31,200.00$ & $35,000.00$ & $40,000.00$ & $45,000.00$ & $50,000.00$ & $\begin{array}{l}70,000.00 \\
1,950.00\end{array}$ & $\begin{array}{c}95,000.00 \\
1,950.00\end{array}$ \\
\hline $\begin{array}{l}\text { Auto/Auto Repairs/expenses } \\
\text { Auto Fund/Payment }\end{array}$ & 120.00 & $122+3$ & 10 & 50.00 & 100.00 & 150.00 & 250.00 & 157.00 & 157.00 & 157.00 & 157.00 & 157.00 & 450.00 & $\begin{array}{c}450.00 \\
3.600 .00\end{array}$ \\
\hline Auto Insurance & & & & 480.00 & 480.00 & 480.00 & 480.00 & 480.60 & 480.60 & 480.60 & 480.60 & 480.60 & 480.60 & $1,200.00$ \\
\hline Cleansing & 180.00 & 180.00 & 180.00 & 180.00 & 180.00 & 180.00 & 180.00 & 180.00 & 180.00 & 180.00 & 180.00 & 180.00 & & 180.00 \\
\hline Dry Cleaning, clothes & 120.00 & 120.00 & 120.00 & 120.00 & 120.00 & 120.00 & 420.00 & 420.00 & 120.00 & 120.00 & 120.00 & 120.00 & 600.00 & 600.00 \\
\hline ing/Cable & 60.00 & 60.00 & 60.00 & 60.00 & 60.00 & 60.00 & 479.64 & 479.64 & 479.64 & 479.64 & 479.64 & 479.64 & $1,259.64$ & $1,259.64$ \\
\hline Family & 240.00 & 240.00 & 240.00 & 480.00 & 480.00 & 480.00 & 480.00 & 480.00 & 480.00 & 480.00 & 480.00 & 480.00 & & 480.00 \\
\hline Food & 480.00 & 600.00 & 600.00 & 900.00 & $1,200.00$ & $1,200.00$ & $2,760.00$ & $2,880.00$ & $2,880.00$ & $2,880.00$ & $2,880.00$ & $2,880.00$ & $4,800.00$ & $4,800.00$ \\
\hline Fees \& Care initial, MO & 56.00 & 56.00 & 56.00 & 56.00 & 56.00 & 56.00 & 56.00 & 56.00 & 56.00 & 56.00 & 56.00 & 56.00 & 76.00 & 76.00 \\
\hline Gas & & & & 240.00 & 240.00 & 240.00 & 240.00 & 240.00 & 240.00 & 240 & 240.00 & 240 & 240.00 & 480.00 \\
\hline Insurance/Co-Pay & 150.00 & 150.00 & 150.00 & 150.00 & 150.00 & 150.00 & 150.00 & 15 & 150.00 & 150 & 15 & 800 & $1,372.00$ & $1,372.00$ \\
\hline +Utilities & $1,080.00$ & $1,440.00$ & 1,56 & 0 & 3,90 & & 7,80 & 9,36 & $10,5 \mathrm{C}$ & 12,5 & 12,5 & 12,5 & 19,2 & 27,0 \\
\hline Tax & 1,0 & (1, & & & & & & & & & & & & 62 \\
\hline Tithe \& Of & 644.00 & 944.00 & 00 & & 1,88 & 2,51 & 4,222 & 4,63 & 00 & 5,5 & $6,012.00$ & & & $10,665.00$ \\
\hline Balance/s & 74.60 & & 57 & & & & & & & & & & & \\
\hline Balance & 2.8 & 14 & & & & & & & & & & & & 296.49 \\
\hline s Percent & $2.07 \%$ & $7.89 \%$ & $11.00 \%$ & 16.6 & $18.24 \%$ & 18.1 & 11.6 & 15.2 & $17.83 \%$ & $18.01 \%$ & 21.4 & 22.8 & $12.15 \%$ & $8.11 \%$ \\
\hline Monthl & 90. & 12 & & & & & & & & & & & & 2,25 \\
\hline Percent & -17.8 & $-19.67 \%$ & $92 \%$ & -15.6 & -14.5 & & -16.2 & & -14.3 & & & & & $-11.23 \%$ \\
\hline $\operatorname{Rec} T$ & 720. & 840.00 & 880.00 & $1,400.00$ & $1,660.00$ & $1,920.00$ & $2,960.00$ & 3,48 & $3,860.00$ & $4,360.00$ & 4,86 & $5,360.00$ & $7,360.00$ & $9,860.00$ \\
\hline Rec Tithe Percent & $0.00 \%$ & $-17.50 \%$ & $6.92 \%$ & $-13.46 \%$ & $-12.77 \%$ & $-12.31 \%$ & $-11.38 \%$ & $-11.15 \%$ & $-11.03 \%$ & $-10.90 \%$ & $-10.80 \%$ & $-10.72 \%$ & $-10.51 \%$ & $-10.38 \%$ \\
\hline
\end{tabular}

Note: Potential Income-Potential Expense (Potential Job Change/Potential Promotion) of strategic

divine resources (2014) of Author, completed.

Source: [Retrieved from]. 


\section{Journal of Economics Bibliography}

\section{Appendix}

A1. Model of Wealth Differences

Let:

$$
\begin{aligned}
& \mathrm{W}_{i j}=\left(1-g-\sum_{q=1} t_{q I}\right) \mathrm{I}_{i j}+\mathrm{A}_{i j}+(1-g)\left(\sum_{q=1} \mathrm{~S}_{q i j}+\mathrm{C}_{i j}\right)-\mathrm{G}_{i j} \\
& \mathrm{I}_{i j}=\sum V=1 W^{\prime} m h h^{\prime} k i j \\
& W^{\prime} m=W k-\delta W(m) j g-\Sigma q=1 t^{\prime} q \\
& h^{\prime} m i j=h m i j-\delta h(m) j g
\end{aligned}
$$

where

$$
\begin{aligned}
& \mathrm{A} i j=[\mathrm{A} 0 i j(1-g-\Sigma q=1 \operatorname{tqA}(0))+\Sigma a=1 \mathrm{~N}(1, a) i j(1-g-\Sigma q=1 t q N(1, a)) \\
& +\Sigma m=1 \gamma \pi(m) i j \pi Z(m) i j(1-g)](1+\gamma \rho i j \rho)(1-\Sigma q=1 t q \rho) \\
& +\Sigma b=1 \mathrm{~N}(2, b) i j(1-g-\Sigma q=1 \operatorname{tq} N(2, b))-\mathrm{G} \rho i j-\delta A j g(\rho, \mathrm{A} 0 i j) \\
& \mathrm{A}_{0 i j}=\mathrm{A}_{0 i j}\left(X_{n 0}, \gamma_{\mathrm{W}(0) i j F} \mathrm{~W}_{0 F}\left(\mathrm{I}_{0}\left(W_{0}, h_{0}, \mathrm{~S}_{0}\right), \mathrm{A}_{0}\left(\mathrm{~A}_{(-1)}, \mathrm{N}_{0}\left(\mathrm{R}_{0}, \mathrm{M}_{0}\right), \gamma_{0}\right.\right.\right. \\
& \left.\left.\left.{ }_{\pi} \pi_{0 Z}\right), t_{o q}, \delta_{o g}, \gamma_{0 \rho}\right)\right) \\
& \pi Z i j=(\mathrm{P} Z j Z i j+\Sigma q=1 \mathrm{~S} q Z i j-\Sigma d=1 P Z(d) j X Z(d) i j)(1-\Sigma q=1 t q \pi) \\
& P_{Z j}=p_{Z}\left(1-\delta_{Z j g}+\Sigma_{q=1} t_{q Z}^{\prime}\right) \\
& \mathrm{Z}_{i j}=\gamma_{Z i j} \Pi_{d=1} X_{Z(d) i j} \beta(d) \\
& P Z(d) j=p Z(d)\left(1-\delta Z(d) j g-\Sigma q=1 t^{\prime} q Z\right) \\
& X Z(d) i j=x Z(d) i j-\delta Z(d) j g
\end{aligned}
$$

To understand the determinants of wealth by groups, consider the following wealth identity:

$$
\mathrm{W}_{w, t}=\exp \left\{\left(1+\mathrm{i}_{w}\right) \mathrm{W}_{w, t-1}+\left(\mathrm{r}_{w, t} \mathrm{~h}_{w, t}-\mathrm{p}_{t} \mathrm{c}_{w, t}\right)\right\}
$$

where $\mathrm{W}_{\mathrm{wf}}$ represents the portfolio of wealth for members of group $\mathrm{w}$, at time $\mathrm{t}=1$...T ; $\mathrm{W}_{\mathrm{wl}-1}$ represents the previous period portfolio of wealth for members of group iv, at time $\mathrm{t}=0$... $\mathrm{T}$ $1 ; i_{w}$. represents the average interest rate earned on previous period portfolio of wealth for members of group $w$, at time $t=1 . . \mathrm{T} ; \mathrm{r}_{\mathrm{ws}}$ represents the wages for group $\mathrm{iv}$, at tune $\mathrm{t}=1 . . \mathrm{T}$; $h$, a represents the number of hours worked for members of group $\mathrm{w}$, at time $\mathrm{t}=1 \ldots \mathrm{T} ; p_{r}$ represents prices for goods consumed at time $\mathrm{t}=1 \ldots \mathrm{T}$; and $c_{m, t}$ represents the goods consumed by members of group $w$, at time $1=1 . . \mathrm{T}$; such that:

$$
W_{w, t}=\exp \left\{\sum_{\tau=1}^{t}\left(1+i_{w}\right)^{t-\tau}\left(r_{w, \tau} h_{w, \tau}-p_{\tau} c_{w, \tau}\right)+\left(1+i_{w}\right)^{t} W_{w, o}\right\}
$$

where $\mathrm{W}_{\mathrm{w}, \mathrm{o}}$ are the initial assets of whites.

Now consider the wealth identity with discrimination or. more specifically, favoritism in favor of members of group $w$. Let $\delta_{\mathrm{k}, \mathrm{w}, \mathrm{t}}$ represent the variable $k$ favoritism coefficient for members of group $w$, at time $\mathrm{t}=1 . . \mathrm{T}$. where $\delta_{\mathrm{k}, \mathrm{w}, \mathrm{t}}>0$ for all variables, such that equation [2] becomes: 


$$
\begin{aligned}
& \text { Journal of Economics Bibliography } \\
& W_{w, t}=\exp \left\{\tilde{W}_{w, t}+F_{w, t}\right\} \\
& \text { where } \\
& \tilde{W}_{w, t}=\sum_{\tau=1}^{t}\left(1+\tilde{i}_{w}\right)^{t-\tau}\left(\tilde{r}_{w, \tau} \tilde{h}_{w, \tau}-p_{\tau} \tilde{c}_{w, \tau}\right)+\left(1+\tilde{i}_{w}\right)^{t} \tilde{W}_{w, o} \\
& F_{w, t}=\delta_{i, w} \sum_{m=1}^{t-\tau} \sum_{s=1}^{t-\tau}\left(1+\tilde{i}_{w}+\delta_{i, w}\right)^{t-m-1}\left(1+\tilde{i}_{w}\right)^{s-1} . \\
& \quad\left(\tilde{r}_{w, \tau} \tilde{h}_{w, \tau}+\tilde{r}_{w, \tau} \delta_{h, w, \tau}+\delta_{r, w, \tau} \tilde{h}_{w, \tau}+\delta_{r, w, \tau} \delta_{h, w, \tau}-p_{\tau}\left(\tilde{c}_{w, \tau}+\delta_{c, w, \tau}\right)\right) \\
& +\delta_{i, w} \sum_{m=1}^{t} \sum_{s=1}^{t}\left(1+\tilde{i}_{w}+\delta_{i, w}\right)^{t-m}\left(1+\tilde{i}_{w}\right)^{s}\left(\tilde{W}_{w, o}+\delta_{W_{o}, w}\right) \\
& +\sum_{\tau=1}^{t}\left(1+\tilde{i}_{w}\right)^{t-\tau}\left(\delta_{r, w, \tau}\left(\tilde{h}_{w, \tau}+\delta_{h, w, \tau}\right)-p_{\tau} \delta_{c, w, \tau}\right)+\left(1+\tilde{i}_{w}\right)^{t} \delta_{W_{o}, w}
\end{aligned}
$$

where tilda represents the variable in absence of discrimination such that $\mathrm{W}_{\mathrm{w}, \mathrm{f}}$ is group $w$ in absence of discrimination (favoritism) at time $\mathrm{t}=1 \ldots \mathrm{T}$, and $F_{w, t}$ is the difference between the observed wealth and wealth in absence of discrimination due to favoritism for members of group IV at time $t=1$...T. The following comparative static analysis shows what happens to wealth with an increase in discrimination, such that:

$$
\begin{array}{cl}
\frac{\partial \ln W_{B, t}}{\partial \delta_{r, B, \tau}}=-\left[\sum_{\tau=1}^{t}\left(1+\tilde{i}_{B}\right)^{-\tau}-\delta_{i, B} \sum_{m=1}^{t-\tau} \sum_{s=1}^{t-\tau}\left(1+\tilde{i}_{B}-\delta_{i, B}\right)^{t-m-1}\left(1+\tilde{i}_{B}\right)^{t-1}\right] h_{B, \tau}<0 & \\
\frac{\partial \ln W_{w, t}}{\partial \delta_{h, w, \tau}}=\left[\sum_{\tau=1}^{t}\left(1+\tilde{i}_{w}\right)^{t-\tau}+\delta_{i, w} \sum_{m=1}^{t-\tau} \sum_{s=1}^{t-\tau}\left(1+\widetilde{i}_{w}+\delta_{i, w}\right)^{t-m-1}\left(1+\tilde{i}_{w}\right)^{s-1}\right] r_{w, \tau} & >0 \\
\frac{\partial \ln W_{w, t}}{\partial \delta_{c, w, \tau}}=-\left[\sum_{\tau=1}^{t}\left(1+\tilde{i}_{w}\right)^{t-\tau}+\delta_{i, w} \sum_{m=1}^{t-\tau} \sum_{s=1}^{t-\tau}\left(1+\tilde{i}_{w}+\delta_{i, w}\right)^{t-m-1}\left(1+\tilde{i}_{w}\right)^{s-1}\right] p_{\tau} \quad<0 \\
\frac{\partial \ln W_{w, t}}{\partial \delta_{W_{e}, w}}=\left(1+\tilde{i}_{w}\right)^{t}+\delta_{i, w} \sum_{m=1}^{t} \sum_{s=1}^{t}\left(1+\tilde{i}_{w}+\delta_{i, w}\right)^{-m}\left(1+\tilde{i}_{w}\right)^{s} & >0 \\
\frac{\partial \ln W_{w, t}}{\partial \delta_{i, w, \tau}}= & \sum_{\tau=1}^{t}(t-\tau+1)\left(1+\tilde{i}_{B}+\delta_{i, w}\right)^{t-\tau}\left(r_{w, \tau} h_{w, \tau}-p_{\tau} c_{w, \tau}\right) \\
& +\sum_{\tau=1}^{t} \tau\left(1+\tilde{i}_{w}+\delta_{i, w}\right)^{\tau-1} W_{w, o}
\end{array}
$$

Equation [4] shows that the size of the increase in log wealth due to a unit increase in wage favoritism depends on the size of the rate of ream', compounded through time, and the number of hours worked. Similarly, equation [5] also shows that the size of the increase in log wealth due to a unit increase in hours-worked fiworitism depends on the size the wage rate and the compounded rate of return. Furthermore, equation [6] shows that the size of the reduction in log wealth due to a unit increase in consumption favoritism depends on the size of the price of commodity consumption and the compounded rate of return. Note that equation [7] shows that the size of the increase in log wealth due to a unit increase in initial wealth discrimination depends solely on the size of the compounded rate of return. Finally, equation [8] shows that the size of the increase in log wealth due to a unit increase in interest rate discrimination depends on the size of initial wealth, periodic savings, and the compounding rate of return. 


\section{Journal of Economics Bibliography}

A Model of Wealth Discrimination

Analogous to equation [2], we can write for blacks:

$$
W_{B, t}=\exp \left\{\sum_{\tau=1}^{t}\left(1+i_{B}\right)^{t-\tau}\left(r_{B, \tau} h_{B, \tau}-p_{\tau} c_{B, \tau}\right)+\left(1+i_{B}\right)^{t} W_{B, o}\right\} .
$$

where $W_{B, t}$ represents the portfolio of wealth for black, $B$, at time $\mathrm{t}=1 \ldots \mathrm{T}$;

$W_{B, t-1}$ represents the previous period portfolio of wealth for blacks, $B$, at time $t=0 . . \mathrm{T}-1 i_{B}$ represents the average interest rate earned on previous period portfolio of wealth for blacks, $B$, at time $\mathrm{t}=1 \ldots \mathrm{T} ; \mathrm{r}_{\mathrm{Bj}}$ represents the wages for blacks. $B$, at time $\mathrm{t}=1 \ldots \mathrm{T} ; h_{B, t}$ represents the number of hours worked for blacks, $B$. at time $\mathrm{t}=1 \ldots \mathrm{T}$; $p_{\mathrm{t}}$ represents prices for goods consumed at time $\mathrm{t}=1 \ldots \mathrm{T}$ : and $c_{B, t}$ represents the goods consumed by blacks, $B$. at time $\mathrm{t}=1 \ldots \mathrm{T}$, and where $W_{B, o}$, is the initial assets of blacks.

Now consider the wealth identity with discrimination or, more specifically, pure discrimination in against members of group $B$. Let $\delta_{\mathrm{k}, \mathrm{B}, \mathrm{r}}$ represent the variable $k$ favoritism coefficient for members of group $B$, at time $t=1 \ldots \mathrm{T}$. where $\delta_{\mathrm{k}, \mathrm{B}, \mathrm{t}}<0$ for all variables, such that equation [4] becomes:

Let $\delta_{\mathrm{k}, \mathrm{B}, \mathrm{t}}=-\delta_{\mathrm{k}, \mathrm{B}, \mathrm{t}}$ where $\delta_{\mathrm{k}, \mathrm{B}, \mathrm{t}}>0$

$$
\begin{aligned}
& W_{B, t}=\exp \left\{\widetilde{W}_{B, t}+D_{B, t}\right\} \\
& \text { where } \\
& \tilde{W}_{B, t}=\sum_{\tau=1}^{t}\left(1+\tilde{i}_{B}\right)^{t-\tau}\left(\tilde{r}_{B, \tau} \tilde{h}_{B, \tau}-p_{\tau} \widetilde{\tau}_{B, \tau}\right)+\left(1+\tilde{i}_{B}\right)^{t} \tilde{W}_{B, o} \\
& D_{B t}=-\delta_{i, B} \sum_{m=1}^{t-\tau} \sum_{s=1}^{t-\tau}\left(1+\tilde{i}_{B}-\delta_{i, B}\right)^{t-m-1}\left(1+\tilde{i}_{B}\right)^{s-1} \\
& \cdot\left(\widetilde{r}_{B, \tau} \tilde{h}_{B, \tau}-\widetilde{r}_{B, \tau} \delta_{h, B, \tau}-\delta_{r, B, \tau} \tilde{h}_{B, \tau}+\delta_{r, B, \tau} \delta_{h, B, \tau}-p_{\tau}\left(\widetilde{c}_{B, \tau}-\delta_{c, B, \tau}\right)\right) \\
& -\delta_{i, B} \sum_{m=1}^{t} \sum_{s=1}^{t}\left(1+\tilde{i}_{B}-\delta_{i, B}\right)^{t-m}\left(1+\tilde{i}_{B}\right)^{s}\left(\tilde{W}_{B, o}-\delta_{W, B}\right) \\
& +\sum_{\tau=1}^{t}\left(1+\tilde{\ddot{B}}_{B}\right)^{t-\tau}\left(-\delta_{r, B, \tau}\left(\widetilde{h}_{B, \tau}-\delta_{h, B, \tau}\right)+p_{\tau} \delta_{c, B, \tau}\right)-\left(1+\tilde{i}_{B}\right)^{t} \delta_{W, B}
\end{aligned}
$$

where tilda represents the variable in absence of discrimination such that $W_{B, t}$ is group $B$ in absence of discrimination at time $\mathrm{t}=1 \ldots \mathrm{T}$, and $D_{B, t}$ is the difference between the observed wealth and wealth in absence of discrimination due to discrimination against members of group $B$ at time $t=1 \ldots$ T. The following comparative static analysis shows what happens to wealth with an increase in discrimination, such that:

$$
\frac{\partial \ln W_{B, t}}{\partial \delta_{r, B, \tau}}=-\left[\sum_{\tau=1}^{t}\left(1+\tilde{i}_{B}\right)^{-\tau}-\delta_{i, B} \sum_{m=1}^{t-\tau} \sum_{s=1}^{t-\tau}\left(1+\tilde{i}_{B}-\delta_{i, B}\right)^{t-m-1}\left(1+\tilde{i}_{B}\right)^{s-1}\right] h_{B, \tau}<0
$$




$$
\begin{aligned}
& \text { Journal of Economics Bibliography } \\
& \frac{\partial \ln W_{B, t}}{\partial \delta_{h, B, \tau}}=-\left[\sum_{\tau=1}^{t}\left(1+\tilde{i}_{B}\right)^{t-\tau}-\delta_{i, B} \sum_{m=1}^{t-\tau} \sum_{s=1}^{t-\tau}\left(1+\widetilde{i}_{B}-\delta_{i, B}\right)^{t-m-1}\left(1+\widetilde{i}_{B}\right)^{s-1}\right] r_{B, \tau}>0 \\
& \frac{\partial \ln W_{B, t}}{\partial \delta_{c, B, \tau}}=\left[\sum_{\tau=1}^{t}\left(1+\tilde{i}_{B}\right)^{t-\tau}-\delta_{i, B} \sum_{m=1}^{t-\tau} \sum_{s=1}^{t-\tau}\left(1+\tilde{i}_{B}+\delta_{i, B}\right)^{t-m-1}\left(1+\tilde{i}_{B}\right)^{t-1}\right] p_{\tau} \quad>0 \\
& \frac{\partial \ln W_{B, t}}{\partial \delta_{W_{o}, B}}=-\left[\left(1+\tilde{i}_{B}\right)^{t}-\delta_{i, B} \sum_{m=1}^{t} \sum_{s=1}^{t}\left(1+\tilde{i}_{B}+\delta_{i, B}\right)^{t-m}\left(1+\tilde{i}_{B}\right)^{s}\right] \quad<0 \\
& \frac{\partial \ln W_{B, t}}{\partial \delta_{i, B, \tau}}=-\sum_{\tau=1}^{t}(t-\tau+1)\left(1+\tilde{i}_{B}-\delta_{i, B}\right)^{t-\tau}\left(r_{B, \tau} h_{B, \tau}-p_{\tau} c_{B, \tau}\right) \\
& -\sum_{\tau=1}^{t} \tau\left(1+\tilde{i}_{B}-\delta_{i, B}\right)^{\tau-1} W_{B, o}
\end{aligned}
$$

Equation [11] shows that the size of the decrease in $\log$ wealth due to a unit increase in wage discrimination depends on the size of the rate of return, compounded through time, and the number of hours worked. Similarly, equation [12] also shows that the size of the reduction in log wealth due to a unit increase in hours-worked discrimination depends on the size the wage rate and the compounded rate of return. Note that equation [13] shows that a unit increase in consumption discrimination can overstate wealth, especially if consumption is forced below subsistence. The size of this effect depends on the price of the commodity and the compounded rate of return from savings in each period

Furthermore, equation [14] shows that the size of the decrease in $\log$ wealth due to a unit increase in initial wealth discrimination depends solely on the size of the compounded rate of return. Finally, equation [15] shows that the size of the decrease in log wealth due to a unit increase in interest rate discrimination depends on the size of initial wealth, periodic savings, and the compounding rate of return.

\section{A Model of Relative Wealth}

In theory, the average wealth of group $B$ is some proportion of the average wealth of group $W$, such that,

$$
\bar{W}_{w, t}=\left(\frac{1}{\phi}\right) \bar{W}_{B, t}
$$

where $1 / \phi$ is the theoretical proportion of wealth. If $\phi$ equals one, then the average wealth of group $B$ is the same the average wealth of w. As $\phi$ goes to zero, the average wealth of w becomes infinity times the average wealth of wimp $B$. As $\phi$ goes to infinity, the average wealth of group w becomes an infinitesimal proportion of the average wealth of the average wealth of group $B$. Let $\phi=e^{-(\lambda \Gamma+\gamma \Lambda)}$, then,

$$
\begin{aligned}
& \frac{\partial \bar{W}_{w, t}}{\partial \Gamma}=\lambda \phi \bar{W}_{B, t} \\
& \frac{\partial \bar{W}_{w, t}}{\partial \Lambda}=\gamma \phi \bar{W}_{B, t}
\end{aligned}
$$

such that,

$$
\begin{aligned}
& \lambda=\sigma+\gamma \\
& \text { where } \sigma=\phi \bar{W}_{B, t}\left(\frac{\partial \bar{W}_{w, t}}{\partial \Gamma}-\frac{\partial \bar{W}_{w, t}}{\partial \Lambda}\right)
\end{aligned}
$$

\section{Copyrights}

Copyright for this article is retained by the author(s), with first publication rights granted to the journal. This is an open-access article distributed under the terms and conditions of the Creative Commons Attribution license (http://creativecommons.org/licenses/by-nc/4.0). 